\title{
SEMANTIC MODELING OF UTILITY NETWORKS IMPLEMENTATION OF USE CASES FOR DEHRADUN CITY
}

\author{
Vishnu E. ${ }^{1, *}$, Sameer $\operatorname{Saran}^{2}$ \\ ${ }^{1}$ Indian Institute of Remote Sensing, Department of Geoinformatics, Dehradun, vishnuedakkat93@gmail.com \\ ${ }^{2}$ Indian Institute of Remote Sensing, Department of Geoinformatics, Dehradun, sameer@iirs.gov.in
}

Commission V, WG V/7

KEY WORDS: OGC CityGML, data model, Utility Network ADE, data storage, utility infrastructure, use cases

\begin{abstract}
:
The current on-going boom in the field of Building Information Modeling (BIM) and 3D GIS is widely being explored for vast urban related applications, analyses and simulations. Large amount of 3D city models are created using various sources of data. Substantial studies are carried out for above-surface features in 3D city models. This ensures providing relevant information about various spatial analyses over the urban systems and environment. Relevant researches explored the numerous applications of 3D GIS such as disaster management, city administration, urban and environment planning, environmental studies, etc. Utility infrastructures (overhead, subsurface or on-surface) play the critical role in the urban space; still they are not considered in 3D city models. OGC CityGML is acting well behind these applications by integrating the geographic information, semantics and the various interdependencies information with the 3D city model. Moreover, comparative studies over the existing network data models make Utility Network ADE as the perfect approach for data modelling. This research proposes the methodology for 3D semantic modelling of subsurface water supply network along with its various 'subsurface, overhead and on-surface' utility network components with the help of OGC CityGML Utility Network ADE. This study is conducted for Dehradun area. As a result, semantically modelled utility network data is utilised for successful implementation of use cases such as 1) areas affected by utility failure; 2) street space affected by utility maintenance; and; 3 ) visualisation. These cases are investigated along with urban space.
\end{abstract}

\section{INTRODUCTION}

Building Information Modeling (BIM) and three dimensional (3D) Geographic Information System (GIS) are used extensively nowadays because of the ability to hold the geometric, semantic, appearance and topographic information of an object. These semantically enriched geographic features are further utilised for geovisualisation, sophisticated simulations and spatial analyses. Open Geospatial Consortium (OGC) City Geographic Markup Language (CityGML) is extensively used in the field of 3D city modeling. CityGML is an official international standard of OGC; XML-based, open data model to store, represent, analyse and exchange the semantically enriched 3D city models. CityGML is an object oriented data model that helps in creating detailed meaningful 3D vector data out from $2 \mathrm{D}$ vector data, non-spatial data and 3D models. Extensive researches were carried out for above surface objects (preferably buildings) with CityGML and were subjected for various simulations and analyses. Subsurface features, mostly utility infrastructures are not been a part of 3D city models even though they forms a major part. Advanced geospatial technologies backed the utility industries through utility mapping, asset management and facility management. Resulting in integration of 3D models and utility data to turn out into 3D data models; highly benefiting various sectors. Visualisation of underground pipelines, its challenges, storage and management are studied (Guerrero, Zlatanova, \& Meijers, 2013). Plentiful applications of 3D city models have been researched and are being practically used by different cities. Utilisation of 3D city models in distinct domains are documented and utilised for further researches (Biljecki, Stoter, Ledoux, Zlatanova, \& Çöltekin, 2015). Basically, the core module of CityGML consists of the basic concepts and components. Thematic modules such as Bridge Module, Tunnel module, etc. will deal with the different thematic fields were CityGML extends the support. CityGML has the provision to extent its support to hold the geographic, appearance, semantic and topographical information by the means called Application Domain Extension. ADEs are developed as per the user requirement to meet the specific applications. There are various ADEs like Noise ADE, Indoor Routing and Positioning (Dutta, Saran, \& Kumar, 2017) and many more. Utility Network ADE is such an extension that supports the semantic modelling of utility infrastructures. The ADE has the ability to represent different utility infrastructures such as water supply, electricity, communication, gas, oil, etc. (Becker, Nagel, \& Kolbe, 2011) designed the first draft of Utility Network ADE for modelling critical infrastructures and their mutual interdependencies in 3D urban space. This ADE satisfies the basic requirement of a common utility network data model that can incorporate distinct utility networks and related information and relationships with 3D urban space; where this feature was desperately lacking in other utility network data models. CityGML is one of the wellknown standard entity for detailed city modeling at discrete LODs (Gröger, Kolbe, Nagel, \& Häfele, 2011). Simultaneously, the provision for extending CityGML with ADEs led to development of Utility Network ADE (Becker, Nagel, \& Kolbe, 2011) aimed at proposing a framework for the dual representation of critical infrastructures. Later, (Becker, Nagel, \& Kolbe, 2012) incorporated functional and semantic aspects into the ADE providing an enriched schema to achieve certain complex analysis and simulations. Research aims at 3D semantic modeling of subsurface water supply utility network using CityGML Utility Network ADE. The potential capabilities of CityGML are already been and being proved in numerous fields of research. So, the need of the research is to 
describe a detailed methodology for semantic modelling of distinct utility networks and their interdependency with urban space using Utility Network ADE.

\section{RELATED STUDIES}

\subsection{OGC CityGML Utility Network ADE}

Current version of OGC CityGML 2.0 is exceptionally used as the common standard open data model for 3D city modeling. These lead to semantically enriched models contributing towards numerous real time and realistic simulations and analysis. Utility network feature classes were not included within the broad themes of CityGML. Reasons like inadequate, imprecise and indistinct spatial information including depth or height of utility service line may cause tragic consequences (Du, Zlatanova, \& Liu, 2006). This work mentioned the relevance of the 3D utility data, as it can convey better understanding and perception about the utility network complexity. Later, researches proposed a semantic framework for the modelling of 3D data and suggested the possibility of database for "manmade and natural features" as well as "below ground and above ground" geographical features (Emgård \& Zlatanova, 2007). Becker et al. (2011) presented an innovative conceptual model called Utility Network ADE for the representation of networks topographically as well as topologically. Relationship between BIM and 3D GIS classes are studied and their mapping is studied well (Hijazi, Ehlers, Zlatanova, \& Becker, 2011).Advanced model was proposed by Becker, Nagel, \& Kolbe (2012) including semantic classes. An attempt for subsurface network data acquisition using GPR and later the acquired data is represented in 3D city model for the institution campus using CityGML Utility Network ADE (Dutta \& Saran, 2016). These innovations paved the path for relevant researches on Utility Network ADE. Kutzner and Kolbe (2016) rendered the real benefits of the ADE by illustrating the information on the city objects as well as supply networks making them suitable for simulations and analysis. Many cities have adopted this as a highly beneficial research topic for utility network planning and management. Hijazi, Kolbe and Kutzner (2017) proposed the requirement of use cases that was suggested by certain experts from different domains and also to evaluate the capability of different network data models. Paper points out that in most cases; CityGML Utility Network ADE is capable of mapping spatial information of different network systems and their relationship with different city entities.

\section{STANDARD NETWORK DATA MODELS}

Several network data models are designed by several organisations focussing on specific utility infrastructure. Purpose of these data models is to create geometric and semantic enriched data as per the requirements. Also, there are advantages as well as disadvantages for each model. Following session will discuss on this context. These data models may or may not support a 3D space; may or may not support distinct utility infrastructures.

\subsection{ESRI Utility Network}

- Two ways of representation supported: Geometrically and Schematically (ESRI, 2016).

- ESRI Geometrical network model: structure of network.

- ArcGIS Schematics: represents semantics.

- 2D GIS based representations.
- It supports simple 3D visualisation.

- Support gas network, water network and electricity.

\subsection{INSPIRE Utility Networks Model}

- It supports Electricity network, Oil, Gas \& Chemicals network, Sewer network, Thermal network, Water network and Telecommunications network (INSPIRE Thematic Working Group Utility and governmental services, 2012).

- $\quad$ Support additional thematic classes.

- Topographic representation of networks.

- Unsuitable for urban and utility infrastructure analyses simultaneously (Kutzner \& Kolbe, 2016).

\subsection{IFC Utility Network Model}

- $2 \mathrm{D}$ and 3D representation.

- Industry Foundation Classes (IFC) is a standard format in Building Information Modelling (BIM) for buildings and construction industry data (ISO 16739:2013, 2013).

- Logical and physical representation in 3D with semantics. Restricted to building scale level.

- It supports spatial relationships between networks as well as networks and city objects.

- It doesn't support for city scale modeling (ISO 16739:2013, 2013).

\subsection{Common Information Model (CIM)}

- CIM is specifically developed for electricity networks.

- It is accepted by International Electrotechnical Commission (IEC).

- IEC 61970-301 defines the standard for sore packages of CIM focussing on electricity transmission like energy management system, SCADA, planning and optimization (IEC 61790-301:2016, 2016).

- XML format for network model exchanges (IEC 61970-501, 2006).

- Support broad semantic modelling describing relationship between each feature, asset tracking, work scheduling and customer billing.

- Limitation: It doesn't support the geometrical modelling of component; i.e., lack in spatial relations.

\subsection{CityGML Utility Network ADE}

- CityGML Utility Network ADE draft was proposed by (Becker et al., 2011).

- It supports structural, topographical, functional and semantic aspects (Becker et al., 2012).

- It supports various storage, analysis, simulations and visualisation.

- It supports multiple networks in 2D and 3D space.

\subsection{Pipeline ML}

- GML-based model that can handle data exchange of pipeline focussing on oil and gas networks (OGC, 2013).

- It doesn't support topological representation.

- It focuses on 2D representations of distribution components. 


\subsection{Inference}

Each network model is having pros and cons. The comparison between several existing network models conclude that Utility Network ADE as more promising one (Hijazi, Kolbe, \& Kutzner, 2017; Kutzner \& Kolbe, 2016). Utility Network ADE supports all kind of utility networks that are above or below surface; also in $2 \mathrm{D}$ as well as $3 \mathrm{D}$ urban space along with wide categories of thematic classes supporting geometrically as well as semantically. This makes the CityGML Utility Network ADE most promising one among existing models (Hijazi et al., 2017). Table 1 shows the characteristics of the aforementioned network data models.

\begin{tabular}{|c|c|c|c|c|c|c|}
\hline Data model & $\begin{array}{l}\text { INSPIRE } \\
\text { Utility } \\
\text { Networks }\end{array}$ & $\begin{array}{l}\text { IFC } \\
\text { Utility }\end{array}$ & $\begin{array}{l}\text { ESRI Utility } \\
\text { Network }\end{array}$ & CIM & Pipeline ML & $\begin{array}{c}\text { CityGML } \\
\text { Utility } \\
\text { Network } \\
\text { ADE }\end{array}$ \\
\hline $\begin{array}{l}\text { Representation } \\
\text { topological/topographical }\end{array}$ & $\checkmark$ & $\checkmark$ & $\checkmark$ & $\checkmark$ & $\checkmark$ & $\checkmark$ \\
\hline 2D Representation & $\checkmark$ & $\checkmark$ & $\checkmark$ & 凶 & $\checkmark$ & $\checkmark$ \\
\hline 3D Representation & 囚 & $\checkmark$ & 口 & 凶 & 凶 & $\checkmark$ \\
\hline $\begin{array}{l}\text { Relationship between different } \\
\text { network features }\end{array}$ & $\checkmark$ & $\checkmark$ & $\checkmark$ & $\checkmark$ & $\checkmark$ & $\checkmark$ \\
\hline $\begin{array}{l}\text { Relationship between network } \\
\text { features \& urban space }\end{array}$ & 冈 & $\nLeftarrow$ & 冈 & 冈 & 凶 & $\checkmark$ \\
\hline Functional aspects & 冈 & 冈 & 凶 & 冈 & 冈 & $\checkmark$ \\
\hline Network Type & Any network & $\begin{array}{c}\text { Any } \\
\text { network }\end{array}$ & Any network & $\begin{array}{l}\text { Electricity } \\
\text { network }\end{array}$ & $\begin{array}{l}\text { Oil \& gas } \\
\text { network }\end{array}$ & Any network \\
\hline
\end{tabular}

Table 1. Comparison between Network Data Models

$\begin{array}{ll}\checkmark & \text { - Support } \\ \mathbf{x} & \text { - No Support }\end{array}$

\section{STUDY AREA, DATASETS AND METHODOLOGY}

\subsection{Study Area}

The proposed study is conducted for three wards of Dehradun city in Uttarakhand state between $30^{\circ} 19^{\prime} 59.91^{\prime \prime}$ north, $30^{\circ} 18^{\prime}$ $23.34^{\prime \prime}$ south latitudes and $77^{\circ} 58^{\prime} 58.58^{\prime \prime}$ west, $78^{\circ} 1^{\prime} 44.47^{\prime \prime}$ east longitudes. The study area map is shown in the Figure 1.

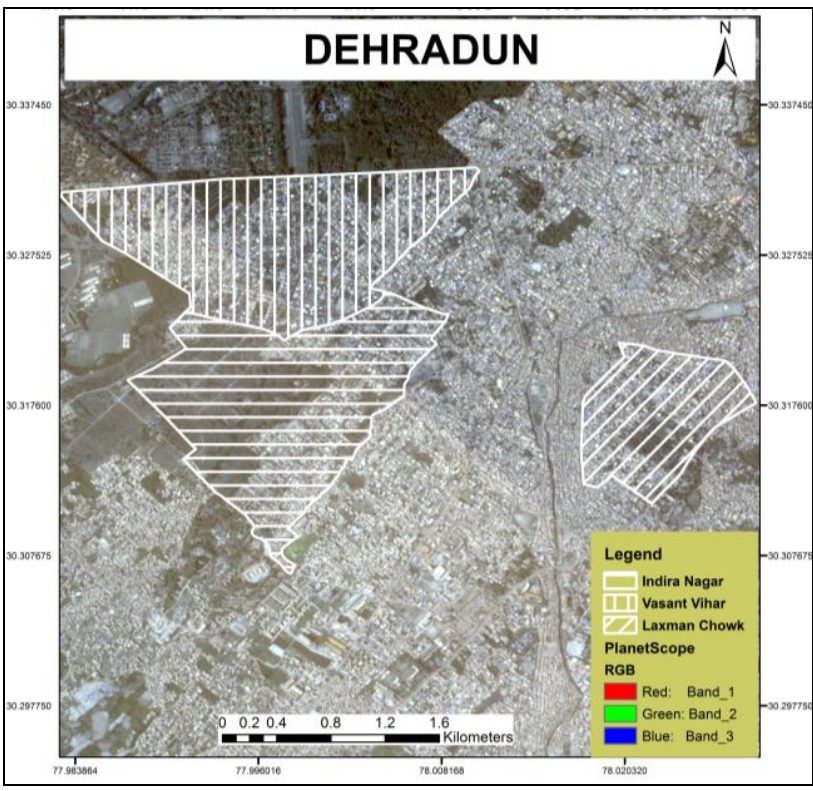

Figure 1. Study Area Map
* - Building Scale support only

- - Only Visualisation

\subsection{Datasets Used}

Various methods are adopted to collect the data; field visit as well as secondary datasets. Table 2 represents the datasets used in the work.

\begin{tabular}{|c|c|c|}
\hline Remote Sensing Data & Primary Data & Secondary Data \\
\hline PlanteScope: & GPS data & Pipeline layout \\
\cline { 2 - 3 } $\begin{array}{c}\text { OrthoTile; 3.125m } \\
\text { spatial resolution }\end{array}$ & Field Data & Road network \\
\cline { 3 - 3 } & & $\begin{array}{c}\text { Network components } \\
\text { location }\end{array}$ \\
\hline
\end{tabular}

Table 2. Datasets

\subsection{Methodology}

Initial stages of assigned task comprise data collection, data preprocessing, data creation and non-spatial data gathering. Then, organised data of subsurface water supply pipelines and network components (on-surface, overhead and subsurface) is used for data modeling using CityGML Utility Network ADE. The methodology is shown in the Figure 2. Data modeling process consists of mapping each network component mapping to its respective feature classes in the Utility Network ADE. $\mathrm{ADE}$ is designed in such a way as it consists of child class, parent class and grandparent class. Data modeling process for subsurface pipeline networks is represented in the following session. CityGML Utility Network ADE is linked with OGC CityGML through CityFurniture class. Open Geospatial Consortium (OGC) CityGML allows 3D modeling of city objects at 5 discrete levels of details (Gröger et al., 2011). CityGML consists of several thematic models for enriched 
modeling of city space. Research work proposes CityGML based data modeling approach for geometrically and semantically enriched utility network. This is one of the unique study or modeling approach dealing with subsurface utility network along with its on-surface and above surface network components.

3D City Modeling

Figure 2. Methodology

Geospatial models are too complex and heavy. The systematic way proposed by (Luebke, Reddy, Cohen, Varshney, \& Huebner, 2003) to overcome the data complexity is through representing the geospatial data by choosing the appropriate LOD models. The proposed study deals with modeling at existing two LOD values: graphical representation (realization) and topographical representation (lodlgeometry).

\section{DATA MODELING AND DATA STORAGE}

Different approaches for representation and exchanging of 3D city models, modeling aspects, relationship between geometry and semantics, different standards are well studied (Kolbe, 2009).Study deals with CityGML Utility Network data modeling approach have been implemented for subsurface water supply network for Dehradun city, India. The study focuses on detailed modeling for the aforementioned network along with the network components located above/below surfaces. Data modeling approach is carried out with Feature Manipulation Engine at two levels of representation: topological and topographical representation. Similarly, data storage is considered to be a critical section. CityGML data consists of geometric and semantic information. This makes CityGML Utility Network ADE data becomes very complex as the number of network components as their relationships with the master components are more in the proposed approach. It yields a hierarchically modelled data, having different levels of feature classes. 3D City Database is specifically developed by TUM. 3DCityDB is a spatial relational database model capable of efficient handling of CityGML datasets. It supports storing, managing and visualising such semantically enriched 3D city models. CityGML ADE data is stored by extending PostgreSQL/PostGIS with 3DCityDB relational database schema developed by (Agugiaro, 2017). Subsequently the spatially extended RDBMS of new tables and columns are populated with the FME (Duijn, 2018).

In addition to study about the effects of subsurface utility maintenance with street space, Transportation model is used to create the CityGML Transportation data. The street space is modelled in basic level of representation and at LOD 1. That is geometrical model consists of edges and nodes at LOD 0 . To perform the spatial analysis between street space and subsurface utility network, LOD 1 representation of street space is used.
Most of the developing countries lack a well-planned and structured utility infrastructure. Rapid growth and development in the areas resulted in an unorganised infrastructure including transportation and utility networks. Also, the utility infrastructures are not well planned. Hence, this use case pays more relevance. This can lead the administrators and urban planners for better evaluation of existing networks.

\subsection{CityGML Based Utility Network Modeling}

Subsurface water supply network is mapped to CityGML Utility Network ADE with respect to literature background and through the detailed study. Utility Network ADE Core module aids in representing the data topologically as well as topographically, as the Core Module can be considered as two sections with aforementioned functions. Topographical representation is performed with the feature class AbstractNetworkFeature.

Firstly, all the feature classes except NetworkLink is used to represent the subsurface utility infrastructure in its graphical form. The task is performed with the help of feature classes such as InterFeatureLinks and InteriorFeatureLink for edge features; point features are represented by Node. The created data has the information of starting and ending nodes that enables the distribution of water supply as per the records of authority. Same information is appended to Utility Network ADE data with the help of transformer named Attribute Renamer. Overhead storage tank is represented as a Node. Similarly, other network components such as hand pumps, hydrants and valves are represented as Node. The same information about starting and ending nodes, also about the connection of network components will ensure better spatial analysis on the semantically modelled data. Simultaneously, these network components such as hand pumps and fire hydrants are mapped as SimpleFunctionElement and their relationship with the edge-like structures are defined through InterFeatureLink as they define the topological relationship between two nodes of separate links. NetworkGraph is the parent class where the entire graphical network is mapped with. FeatureGraph represents the relationship between the network components and edge-like structures. Topologically or graphically the utility network representation or modeling is done in a two dimensional urban space with LOD value "realization".

Secondly, description about topographical representation of subsurface water supply networks begins with mapping of each component into its feature classes. Feature classes are selected from different existing modules of Utility Network ADE such as Network Core, Network Property, Feature Material, and mainly Network Components. The feature classes for each network component are as follows. Pipelines mapped to RoundPipe feature class. RoundPipe inherits the properties of AbstractDistributionElement feature class. Topographical modeling of infrastructure including pipelines and network components are performed in a three dimensional urban space. Buildings are mapped as the TermialElement as well as Building feature class. Overhead water tank is mapped as StorageDevice. Fire hydrants and hand pumps are mapped as TerminalElement, SimpleFunctionalElement and CityFurniture. Valves are mapped as ControllerDevice and SimpleFunctionalElement. These feature classes are represented with respect to their location, height or depth information as per the real network. This task of assigning the elevation or depth information is implemented in the data model with the help of 
transformer named 3DForcer in the FME. All the feature classes are mapped to AbstractNetworkFeature. AbstractDistributionElement inherits the properties of AbstractNetworkFeature. The feature classe such as LiquidMedium is used to add more non-spatial information into the data model regarding the commodity that is being supplied in the pipeline. LiquidMedium inherits the properties of AbstractCommodity. Network class will represent complete network components and other properties of network. It is the parent class. The entire components in topographical modeling are provided with LOD value "lod1Geometry". Table 3 shows the details about mapping of components or devices to their respective CityGML Utility Network ADE feature classes.

\begin{tabular}{|c|c|c|}
\hline Class & $\begin{array}{l}\text { Topographical } \\
\text { representation }\end{array}$ & $\begin{array}{c}\text { Topological } \\
\text { representation }\end{array}$ \\
\hline \multirow[t]{3}{*}{ Pipeline } & \multirow[t]{3}{*}{ Round Pipe } & InteriorFeatureLink \\
\hline & & InterFeatureLink \\
\hline & & FeatureGraph \\
\hline Valves & Controller Device & \multirow{8}{*}{ Nodes } \\
\hline $\begin{array}{l}\text { Overhead } \\
\text { Tank }\end{array}$ & Storage Device & \\
\hline \multirow[t]{2}{*}{ Hand pumps } & Terminal Element & \\
\hline & $\begin{array}{c}\text { Simple Functional } \\
\text { Element }\end{array}$ & \\
\hline \multirow[t]{2}{*}{ Fire hydrants } & Terminal Element & \\
\hline & $\begin{array}{c}\text { Simple Functional } \\
\text { Element }\end{array}$ & \\
\hline \multirow[b]{2}{*}{ Buildings } & Buildings & \\
\hline & Terminal Element & \\
\hline
\end{tabular}

Table 3. Mapping Subsurface Features to CityGML Feature Classes

Information such as diameter of pipe, elevation/depth from ground, elevation and size of storage tank, etc. are included while semantically modeling the utility network data. Finally, the CityGML data consists of various spatial and non-spatial information along with the relationship between the components categorised into distinct feature classes. This makes the data complex. Hence, a relational database schema is required for the storage purpose. This is described in the following section.

\subsection{Data Storage}

As mentioned in the previous section, CityGML Utility Network ADE data has to be stored in a well-designed spatially extended Relational Database Management System (RDBMS). Handling and managing of these large 3D datasets, role of DBMS, visualisation of data in DBMS are explored (Zlatanova, 2006; Zlatanova \& Stoter, 2006). Data can be large, bulky as well as categorised or organised as parent-child relationships. Therefore, an efficient storage system is mandatory for CityGML data. CityGML is an object oriented data model. An initiative for storage of dataset was carried out by (Stadler, Nagel, König, \& Kolbe, 2009). CityGML and its thematic model data are finally mapped to such a spatially extended relational database management system (RDBMS); called 3DCity Database. 3DCityDB relational database schema is used to extend the PostreSQL/PostGIS to store the CityGML data. 3DCityDB is an open source package that support storage, import and export, manages, analyse and visualise 3D city models. Unfortunately, ADE data cannot be directly stored into it. Extending the support of 3DCityDB is performed by running scripts as proposed by (Agugiaro, 2017). Spatially extended database is further developed in this way to have the provision for CityGML ADE data storage. This task is achieved by mapping certain CityGML feature classes to new Tables; i.e. Object Oriented CityGML feature classes are mapped to Relational database tables along with their relationship. One or more classes are mapped into a single table. And the relationship between the feature classes make new table. Each attribute in the feature class will turn out into new columns. CityObject class will play the role of base. It aggregates to CityModel which represents a complete 3D city model. CityFurniture is another class that is linked to CityObject. Or, CityObject comprise of CityFurniture. Table 4 shows the mapping of classes in object oriented data model to the tables in the relational data model for storing the water supply network elements.

\begin{tabular}{|c|c|}
\hline Feature class & Relational Database Table \\
\hline $\begin{array}{c}\text { InterFeatureLink } \\
\text { InteriorFeatureLink } \\
\text { NetworkLink }\end{array}$ & utn9_link \\
\hline Node & utn9_node \\
\hline FeatureGraph & utn9-feature_graph \\
\hline RoundPipe & utn9_distrib_element \\
\hline $\begin{array}{c}\text { SimpleFunctionalElement } \\
\text { (Hydrant, Hand pumps) } \\
\text { Roundpipe } \\
\text { Network }\end{array}$ & cityobject \\
\hline Storage Device & utn9_storage \\
\hline Liquid Medium Supply & utn9_medium_supply \\
\hline Network & utn9_network \\
\hline NetworkGraph & utn9_network_graph \\
\hline
\end{tabular}

Table 4: Mapping of classes to tables for Water Supply Data Storage

This relationships and mapping of classes are described (Agugiaro, 2017). Arbitrary CityGML ADE handling research is being conducted (Zhihang \& Kolbe, 2017). Present case, extension of database is done with the help of certain scripts. Each table will be having one primary key. Then with the help of FME, CityGML Utility Network ADE data is stored into the spatially extended RDBMS. This specific approach is being carried out to populate the tables and columns of the database.

\section{IMPLEMENTATION OF USE CASES: RESULTS}

Utility infrastructure information with in the $3 \mathrm{D}$ city model is useful as it holds the relationships between "city objects and utility networks' as well as with in the utility networks. Various applications such as utility planning and management, disaster management, urban planning can be carried out with detailed representations. The section will discuss three use cases; where first is effect of utility network updating/repair on the road network or street space, next is utility network failure and areas affected by it and finally visualisation of semantic 3D model. Detailed 3D city models contribute a lot in various spatial analyses and applications. These can aid in optimal supply of commodities, installation cost, maintenance cost and cascading effects at the time of failure in network components.

\subsection{Areas Affected from Utility Network Failure}

Stored data is utilised to perform spatial analysis which yields the areas affected from water supply pipeline failure. This task can be considered on two aspects either valve closure or damage due to trenching. Figure 3 shows the analysed result. 
The red dot in the figure shows the location of failure. The green line features shows with the supply, whereas red lines shows the areas where distribution is disturbed. The query is written to do the analysis for smaller area.

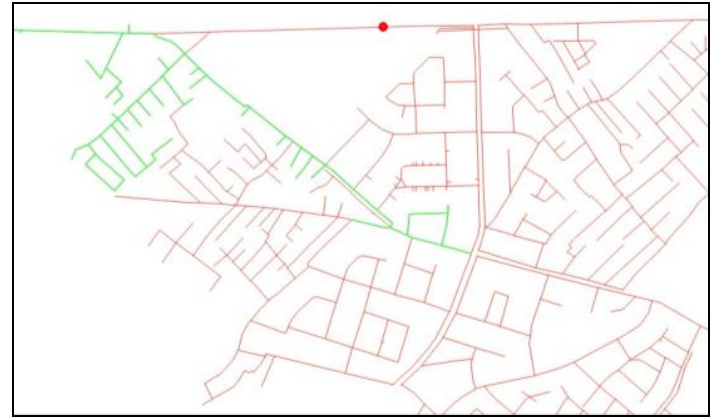

Figure 3. Water pipeline failure and affected areas

\subsection{Utility Networks Along with Street Space}

Most of the cities are supplied with the utility networks along the road networks. Many underdeveloped and developing areas are subjected to directly affected due to utility network excavation or repairing. As mentioned in (Beil \& Kolbe, 2017), infrastructure planning and management is directly related with street space. Most cases of cities have manholes over the roads; at the time of rain and sewer blockage, resulting in overflow of storm water and sewer to spell over the roads. Water supply lines at several areas will be directly below the area covered by road. Figure 4 shows the effected street spaces due to infrastructure repairs because of roads overlaying on utility infrastructures. The roads in blue colour show the roads that are not affected, whereas roads or polygons in yellow colour represent the affected roads at the time of utility network maintenance. As the improper road widening led to this scenario. This scenario is widely observed during the analysis time.

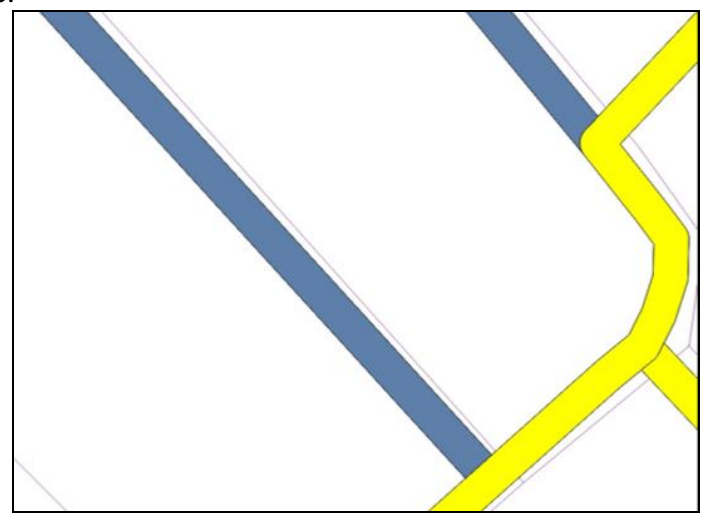

Figure 4. Street spaces affected during pipeline repairs

\subsection{Visualisation of Utility Network ADE data}

Regions with poorly planned utility infrastructures will have high benefits with detailed sematic models. Figure 5 represents the topographical representation of utility networks. The figure shows the subsurface water pipelines and components and overhead storage tanks. This evidently describes the ADE is potential to represent the geographical features and related information to it. Graphical representation of utility network is performed in two-dimensional space along with footprints of buildings. While, topographical representation is performed in three-dimensional environment along with urban space and street space, i.e. 3D building models and roads. Street space is modelled at LOD 0 and LOD 1 using CityGML Transportation Model.

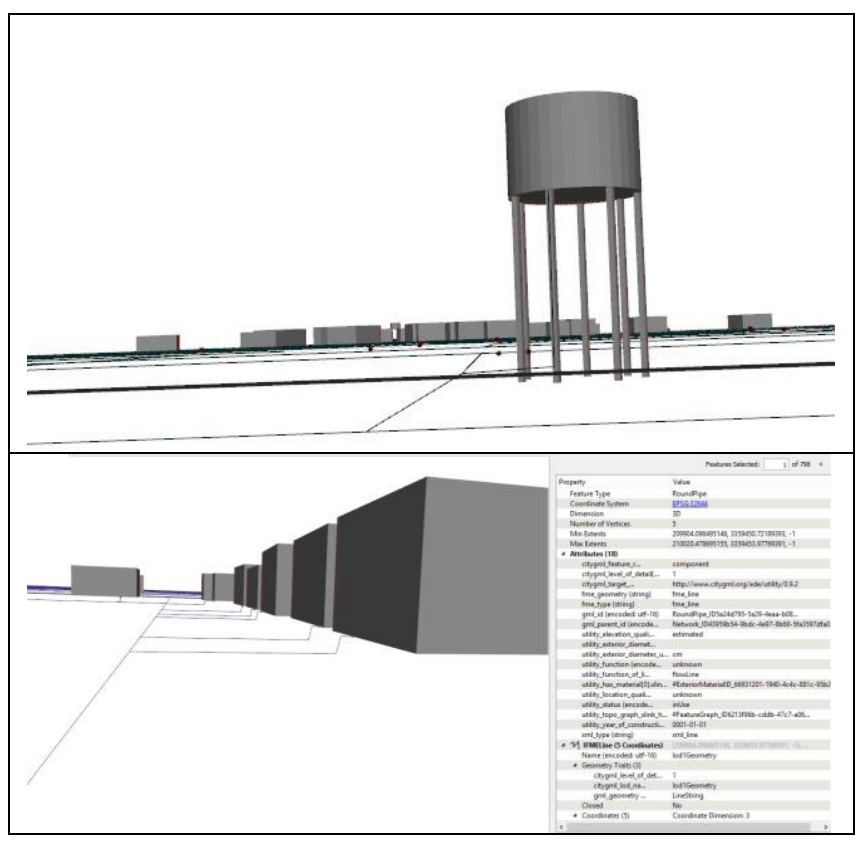

Figure 5. Topographical model of water supply network

\section{CONCLUSION}

Even though several utility network data models are existing; literature survey and proposed research concludes that the CityGML Utility Network ADE is the most efficient one. Each utility network will have its own properties and characteristics. This data model is capable of storing diverse characteristics of subsurface utility networks, its geometry and semantics. Moreover, it is having great potential to represent the relationship within the utility networks as well as relationship between utility network and other city objects. The research work indicates the features of existing information model's capability of modeling of utility networks along with urban and street space. Proposed study successfully achieved the modeling of subsurface utility network, i.e. water supply network along with several network elements which are present on-surface, above surface and subsurface. Relational database with spatial extension is populated by different network elements and their related properties at the supported LODs of existing ADE. Semantically enhanced utility networks and efficient DBMS are utilised effectively for utility management and analysis tasks. Study illustrates three use cases and its implementation as the results. The existing ADE is able to incorporate the fundamental elements and their characteristics in 2D and 3D space; contributing for sophisticated analyses and simulations. As an extension of this work, multiple utility network modeling and storage is planned as a future work. These also help in determining interdependencies and spatial relationships of overhead and subsurface networks in the $3 \mathrm{D}$ city models.

\section{References}

Agugiaro, G. (2017). 3D City Database extension for the CityGML Utility Net- work ADE. https://github.com/gioagu/3dcitydb_ade/tree/master/03_ utility _network_ade. Accessed: 2017-10-30. 
Becker, T., Nagel, C. and Kolbe, T.H., 2011. Integrated 3D modeling of multi-utility networks and their interdependencies for critical infrastructure analysis. In Advances in $3 D$ GeoInformation Sciences (pp. 1-20). Springer, Berlin, Heidelberg. https://doi.org/10.1007/978-3-642-12670-3

Becker, T., Nagel, C. and Kolbe, T.H., 2013. Semantic 3D modeling of multi-utility networks in cities for analysis and 3D visualization. In Progress and New Trends in 3D Geoinformation Sciences (pp. 41-62). Springer, Berlin, Heidelberg. https://doi.org/10.1007/978-3-642-29793-9-3

Beil, C. and Kolbe, T.H., 2017. CityGML and the streets of New York-A proposal for detailed street space modelling:(accepted). In Proceedings of the 12th International $3 D \quad$ GeoInfo Conference 2017 (pp. 9-16). https://doi.org/10.5194/isprs-annals-IV-4-W5-9-2017

Biljecki, F., Stoter, J., Ledoux, H., Zlatanova, S. and Çöltekin, A., 2015. Applications of 3D city models: State of the art review. ISPRS International Journal of Geo-Information, 4(4), pp.2842-2889. https://doi.org/10.3390/ijgi4042842

Du, Y., Zlatanova, S. and Liu, X., 2006, September. Management and 3D visualisation of pipeline networks using DBMS and AEC software. In Proceedings of the ISPRS commission IV symposium on geospatial databases for sustainable development (pp. 27-30).

den Duijn, X., 2018. A 3D data modeling approach for integrated management of below and above ground utility network features.

Dutta, A. and Saran, S., 2016. Short Note 3D modeling of subsurface utilities using Ground Penetrating Radar (GPR) data. Journal of Geomatics, 10(2).

Dutta, A., Saran, S. and Kumar, A.S., 2017. Development of CityGML application domain extension for indoor routing and positioning. Journal of the Indian Society of Remote Sensing, 45(6), pp.993-1004. https://doi.org/10.1007/s12524017-0665-y

Emgard, K.L. and Zlatanova, S., 2007. Design of an integrated 3D information model. Urban and regional data management: UDMS annual, pp.143-156.

ESRI. (2016). Road Ahead for Network Management.

Gröger, G., Kolbe, T.H., Nagel, C. and Häfele, K.H., 2012. OGC city geography markup language (CityGML) encoding standard, Version 2.0, OGC doc no. 12-019. Open Geospatial Consortium. 1-344. https://doi.org/OGC 12-019

Guerrero, J.M., Zlatanova, S. and Meijers, B.M., 2013. 3D visualisation of underground pipelines: best strategy for 3D scene creation. In 8th 3DGeoInfo Conference \& WG II/2 Workshop, Istanbul, Turkey, 27-29 November 2013, ISPRS Archives Volume II-2/W1. ISPRS.

Hijazi, I., Ehlers, M., Zlatanova, S., Becker, T. and van Berlo, L., 2011. Initial investigations for modeling interior Utilities within 3D Geo Context: Transforming IFC-interior utility to CityGML/UtilityNetworkADE. In Advances in 3D Geoinformation sciences (pp. 95-113). Springer, Berlin, Heidelberg. https://doi.org/10.1007/978-3-642-12670-3
Hijazi, I., Kutzner, T. and Kolbe, T.H., 2017. Use Cases and their Requirements on the Semantic Modeling of 3D Supply and Disposal Networks. In Kulturelles Erbe erfassen und bewahren-Von der Dokumentation zum virtuellen Rundgang, 37. Wissenschaftlich-Technische Jahrestagung der DGPF (pp. 288-301)

IEC 61790-301:2016. (2016). IEC 61970-301:2016 | IEC Webstore | automation, cyber security, smart city, smart energy, smart grid, CGMES. Retrieved April 25, 2018, from https://webstore.iec.ch/publication/31356

IEC 61970-501. (2006). International Standard. Order A Journal On The Theory Of Ordered Sets And Its Applications, 6.

INSPIRE Thematic Working Group Utility and governmental services. (2012). D2.8.III.6 INSPIRE Data Specification on Utility and governmental services - Draft Technical Guidelines, (March), 233.

ISO 16739:2013. (2013). ISO 16739:2013 - Industry Foundation Classes (IFC) for data sharing in the construction and facility management industries. Retrieved April 25, 2018, from https://www.iso.org/standard/51622.html

Kolbe, T.H., 2009. Representing and exchanging 3D city models with CityGML. In $3 D$ geo-information sciences (pp. 1531). Springer, Berlin, Heidelberg. https://doi.org/10.1007/9783-540-87395-2_2

Kutzner, T. and Kolbe, T.H., 2016. Extending semantic 3D city models by supply and disposal networks for analysing the urban supply situation. In Lösungen für eine Welt im Wandel, Dreiländertagung der SGPF, DGPF und OVG, 36. Wissenschaftlich-Technische Jahrestagung der DGPF (pp. 382394).

Luebke, D., Reddy, M., Cohen, J.D., Varshney, A., Watson, B. and Huebner, R., 2003. Level of detail for $3 D$ graphics. Morgan Kaufmann.

OGC. (2013). PipelineML. Retrieved April 26, 2018, from http://pipelineml.org/tour/pipelineml-definition/

Stadler, A., Nagel, C., König, G. and Kolbe, T.H., 2009. Making interoperability persistent: A 3D geo database based on CityGML. In 3D Geo-information sciences (pp. 175-192). Springer, Berlin, Heidelberg.

Yao, Z. and Kolbe, T.H., 2017. Dynamically extending spatial databases to support CityGML application domain extensions using graph transformations. In Kulturelles Erbe erfassen und bewahren-Von der Dokumentation zum virtuellen Rundgang, 37. Wissenschaftlich-Technische Jahrestagung der DGPF (pp. 316-331).

Zlatanova, S., 2006. 3D geometries in spatial DBMS. In Innovations in $3 D$ geo information systems (pp. 1-14). Springer, Berlin, Heidelberg. https://doi.org/10.1007/978-3540-36998-1_1

Zlatanova, S. and Stoter, J., 2006. The role of DBMS in the new generation GIS architecture. In Frontiers of geographic information technology (pp. 155-180). Springer, Berlin, Heidelberg. https://doi.org/10.1007/3-540-31305-2_8 